\title{
The great chain of being is still here
}

\author{
Emanuele Rigato ${ }^{* \dagger}$ and Alessandro Minelli ${ }^{\dagger}$
}

\begin{abstract}
Background: Professional papers in evolutionary biology continue to host expressions in agreement with the preevolutionary metaphor of the scala naturae (the great chain of being), when contrasting 'lower' to 'higher' representatives of a given branch of the tree of life. How pervasive is the persistence of progressionist, preevolutionary language in contemporary papers?

Results: We document here the prevalence of this unexpected linguistic survival in papers published between 2005 and 2010 by 16 top scientific journals, including generalist magazines and specialist journals in evolutionary biology. Out of a total of 67,413 papers, the unexpectedly high figure of 1,287 (1.91\%) returned positive hits from our search for scala naturae language.

Conclusions: A quantitative appreciation of the survival of progressionist language in scientific papers is the first step towards its eradication. This will obtain by improving skills in tree thinking as well as by more careful editorial policy.
\end{abstract}

Keywords: Scala naturae, Evolutionary trends, Tree thinking, Bibliometric analysis

\section{Background}

The scala naturae, or great chain of being (Lovejoy 1936), as presented by Charles Bonnet in his Insectologie (Bonnet 1745), distributed nature's products, living beings included, from the lowest steps of the ladder occupied by fire, air and water, up to the highest steps hosting monkeys, apes and humans, but there are not lower and higher branches in the evolutionary tree of life. Apart from the strict linearity (as opposed to branching pattern) of the suggested arrangement, and its extension spanning the whole diversity of Earth's natural objects (Linnaeus' tria Regna Naturae, cf. his Systema Naturae of 1735 and following editions), an unbridgeable gap between the arrangement of living beings within Bonnet's ladder of nature and any possible pattern of relationships among living organisms as seen from an evolutionary perspective is due to complete lack of historical perspective (genealogical continuity in particular) in the former, whereas history and genealogical continuity (Darwin's common descent with modification) are the core of any evolutionary views of living beings. As a consequence, we should not expect in the current professional literature in biology, and evolutionary

\footnotetext{
* Correspondence: leistus9@yahoo.it

${ }^{\dagger}$ Equal contributors

Department of Biology, University of Padova, Via Ugo Bassi 58 B, I 35131
} Padova, Italy biology in particular, any survival of scala naturae thinking, or of the corresponding language. These expectations, however, fail to be supported by facts. In the current academic literature, the use of progressionist linguistic expressions, perfectly compatible with a scala naturae worldview, are still quite common to date, apparently replacing the concept of a static ladder of ontological levels with an "evolutionary scale" of progress (Ruse 1996) - less to more adapted, less to more complex, less to more evolved - in which humans are commonly selfdesigned as "highest".

\section{Is progressionist language a problem?}

“Talk of 'higher' and 'lower' organisms ... does not so much reflect a specific misunderstanding of phylogenetic diagrams per se but a failure to grasp the very concept of common descent" (Gregory 2008, p. 126). In fact, "although it is clearly a critical first step, recognizing evolution as tree-like does not in itself eliminate progressionist interpretations of life history" (Gregory 2008, p. 127). The widespread misconceptions about tree-thinking affect ill-informed people, students (Meir et al. 2007), as well as professionals, as we will discuss below.

But this is not just an academic issue: the dangerous consequences of keeping a progressionist language alive extend, potentially at least, to critically important social

\section{Springer}


issues: "an abandonment of progressivism in evolution rightfully undermines the unfortunate conflation of Darwinian evolutionary biology with social Darwinism. ... Social Darwinism involves notions such as inherent progress in evolution and inherently favored classes or groups of humans as a basis for moral norms and social attitudes and action.... With regard to understanding the role of progress in evolution, the implications for getting evolution wrong are much graver than simply getting it wrong" (Johnson et al. 2012, p. 137).

If even the most specialized scientific community is not free from this problem, how it is possible that nonexperts are?

\section{The topology of evolutionary change}

Despite the explosion of tree-like diagrams in the recent biological literature, evolution is indeed often perceived as a linear, progressive process rather than as a story of unceasing branching and diversification ultimately resulting in a tree. This misleading progressionism is scientifically undefensible (e.g., Dawkins 1992; O’Hara 1992, 1997; Gould 1994, 1996; Nee 2005; Gregory 2008; Omland et al. 2008; Casane and Laurenti 2013).

Nothing changes if we replace the old and perhaps naïve terms 'lower' and 'higher' with more technical terms, such as 'primitive' and 'advanced', or 'plesiomorphic' and 'apomorphic'. Primitive (or plesiomorphic) vs. advanced (or apomorphic) can be predicated of characters, but not of species: "all species are mosaics of plesiomorphic and apomorphic traits, and it is inappropriate to speak of plesiomorphic and apomorphic species. One can speak of sister-group relationships or of relative position in a phylogenetic tree." (Brooks and McLennan 1991, p. 68).

Unfortunately, contrary to a widespread belief, the continuing use of 'lower' and 'higher' is not just a verbal practice, only formally incompatible with tree thinking.

As noted by Johnson et al. (2012, p. 129) "old ideas not only die hard, but they can also leave behind subtle warps of attitude and language ... Our failure as biologists and educators to eradicate this misconception has allowed it to linger in the public perception of evolution", as also noted, for example, by Gould (1997) and MacDonald and Wiley (2012).

From an educational perspective, Werth (2012) has recently remarked that students referring to "higher" and "lower" life forms retain an Aristotelian view of the great chain of being, a wrong view of evolution to be corrected by training them in the theory and practice of cladistics.

Correct reading of the tree of life is indeed less common than we should expect. Besides the persistence of the progressionist language ('lower' vs. 'higher') discussed below, based on data extracted by the recent literature, let us briefly consider the widespread use of 'basal', as applied (illegitimately) to a branch of the tree of life, or to a terminal taxon, rather than (legitimately, in a comparative context) to a node. Krell and Cranston (2004) have forcefully argued that this use, simply, does not make sense, as both branches originating from a node are of equal age and (in some sense at least) have undergone equivalent evolutionary change. Parallel to what we argue in this paper of labeling taxa as 'lower' or 'higher', "Considering clades or taxa as 'basal' is not only sloppy wording, but shows misunderstanding of the tree and may have severe semantic and argumentative implications" (Krell and Cranston 2004, p. 280). In front of a rooted cladogram, many authors ask: "Which of the species is the oldest? Which is youngest? Which is most ancestral? Most derived? Most primitive? Most advanced? Most simple? Most complex? The answer is that a phylogeny provides no information about any of these questions! While this answer may seem inconvenient to researchers looking to phylogenies to provide that information, these are the incorrect questions to be asking" (Omland et al. 2008 , p. 856); "the phylogenetic position in a clade of living organisms allows no reliable predictions about an organism's attributes" (Jenner and Wills 2007, p. 315).

\section{Complexity}

One may be tempted to defend the progressionist language by referring to a putative macroevolutionary trend towards increasing degrees of complexity. Let us ignore here the tricky problem of measuring complexity or, at least, of measuring it in a biologically sensible way; on this issue, see, for example McShea (1991, 1993, 1996, 2000, 2001). The idea that complexity (however defined) of living organisms increases (by default) with time has been recently reinforced by McShea and Brandon's (2010) thesis, according to which this trend is intrinsic to evolution as a history of change and primarily independent from selection. The idea of increasing production of complexity in evolution can be explained through a passive process (Carroll 2001) that generates very different patterns compared to the progressionist views supported in various nuances by Lamarck (1809), Lankester (1880) or Spencer (1891). The random walk of evolution exploring the space of complexity cannot exceed the wall of minimal complexity beyond which life is not possible. This may involve an increase in complexity variance, but the modal value does not change, creating a distribution with a small, but longer and longer tail at the high complexity end.

Evolution seems to follow an intrinsic trend towards increasingly complex organisms as a result of people concentrating on the small number of large, complex organisms that inhabit the right-hand tail of the complexity distribution and ignoring the simpler and much more common organisms (the 'full-house' fallacy, Gould, 1996). 
However, as extant members of all living lineages have the same age (as distance from the last common ancestor), thus their expected default complexity would be the same: if it is not, something must have happened to the individual lineages and this something cannot be simply predicted from the position in the phylogenetic tree of the nodes at which these lineages diverged.

Complexity is frequently subjected to decrease. This is not necessarily associated with adaptive regressive trends, as in locomotory organs of parasites, or the digestive system of tapeworms and acanthocephalans, or the eyes of subterranean animals. Decrease in complexity is often initiated, or triggered, by changes in developmental mechanics.

According to the popular macroevolutionary principle known as Williston's Rule (or Williston's Law!), serially repeated parts should occur in numerically abundant and qualitatively uniform series in 'older' or 'primitive' clades, and in progressively lesser number, accompanied by increasing structural and functional divergence, in 'more recent' or 'advanced' clades. However, this putative trend is very frequently reversed. Examples: (i) very numerous, uniform teeth in dolphins (a derived feature only found in a small clade nested within the mammalian radiation), (ii) numerous digits and numerous phalanges per digit in ichthyosaurs (a derived feature only found in a small clade nested within the reptilian radiation), (iii) segment numbers high (sometimes very high) and variable in two distinct clades of centipedes (contrasted with lower and fixed number - 15 pairs of leg-bearing segments - representing the plesiomorphic condition in centipedes). All these examples point to transitions opposite to the trend to be expected according to Williston's principle (Minelli 2003). In all these examples, increase in the number of units (teeth, digits, phalanxes, segments) is accompanied by reduction (up to disappearance) of the differences between neighboring units (i.e., by a change from heteronomous to homonomous seriality). To conclude, with Werth (2012, p. 2135): "Complexity may be a trend, but it is not an inevitability. Naturalistic explanations can be offered for life's diversity, but they need not imply a forward or upward march".

\section{Methods}

How widespread is this phenomenon in the professional literature today is, however, something that nobody has addressed based on a scientometric analysis, except for a small sampling performed by Mogie (2000), who looked for the presence of 'lower' or 'higher' taxa in the titles of some 700 articles published between 1995 and 1999.

Instances of this pre-evolutionary language can be easily found in the most diverse kinds of academic journals. To provide factual evidence to back up a critical assessment of the problem, we mined professional journals for quantitative and qualitative data, asking how pervasive is the persistence of pre-evolutionary language in contemporary papers. We present here the results of a data mining exercise extending over the 67,413 biological articles published between 2005 and 2010 in the three topranking general-science magazines (Science, Nature and Proceedings of the National Academy of the United States of America) as well as in the pages of a dozen qualified biological journals, including the few top ones in evolutionary biology.

We aimed at discovering examples of scala naturae language. This is generally expressed by contrasting lower with higher representatives of a larger or smaller branch of the tree of life: for example, lower vs. higher vertebrates, lower vs. higher plants, and so on. We searched the database with "low X" and "higher X" searching strings, where $X$ took the following values: species, organisms, eukaryotes, algae, plants, animals, metazoans, invertebrates, chordates, vertebrates, fishes, reptiles, mammals, primates. This way, we extracted from the journals' databases all articles containing at least one of these expressions. We checked each sentence containing one of the search strings individually to persuade ourselves that no different or even opposite meanings were actually implied, but only a negligible amount of all returned strings were not real examples of a lower $\mathrm{X}$ vs. higher $\mathrm{X}$ contrast.

We analyzed the relevant papers also in terms of the countries of authors' current affiliation. Rough figures extracted from the PubMed database were corrected because of their underestimation, due to the fact that PubMed's searches are performed only on title and abstract, making our searches blind to most of the text (full-text). Assuming that the probability to get a hit is linearly proportional to the length of the text, we calculated, by full-text searches on journals' databases (a sample of eight random chosen journals), a correction factor of 8 which allowed us to correct PubMed's percentages, taking the articles' average length into account.

\section{Results and discussion}

Our search on journals' databases (Figure 1) eventually spanned over a total of 67,413 articles. Of these, 1,287 (1.91\%) returned positive hits from our search for scala naturae language. In percentage terms, these figures are quite marginal, but the same cannot be said in absolute terms. Moreover, in a few journals the percentage of articles we identified as containing pre-evolutionary language occurred at a quite higher rate. Interestingly, this happened especially for specialist journals in evolutionary biology. This goes against the expectation for a more accurate exclusion of linguistic expressions in fundamental contrast to the basic cultural perspective from which should arguably move an investigation in 

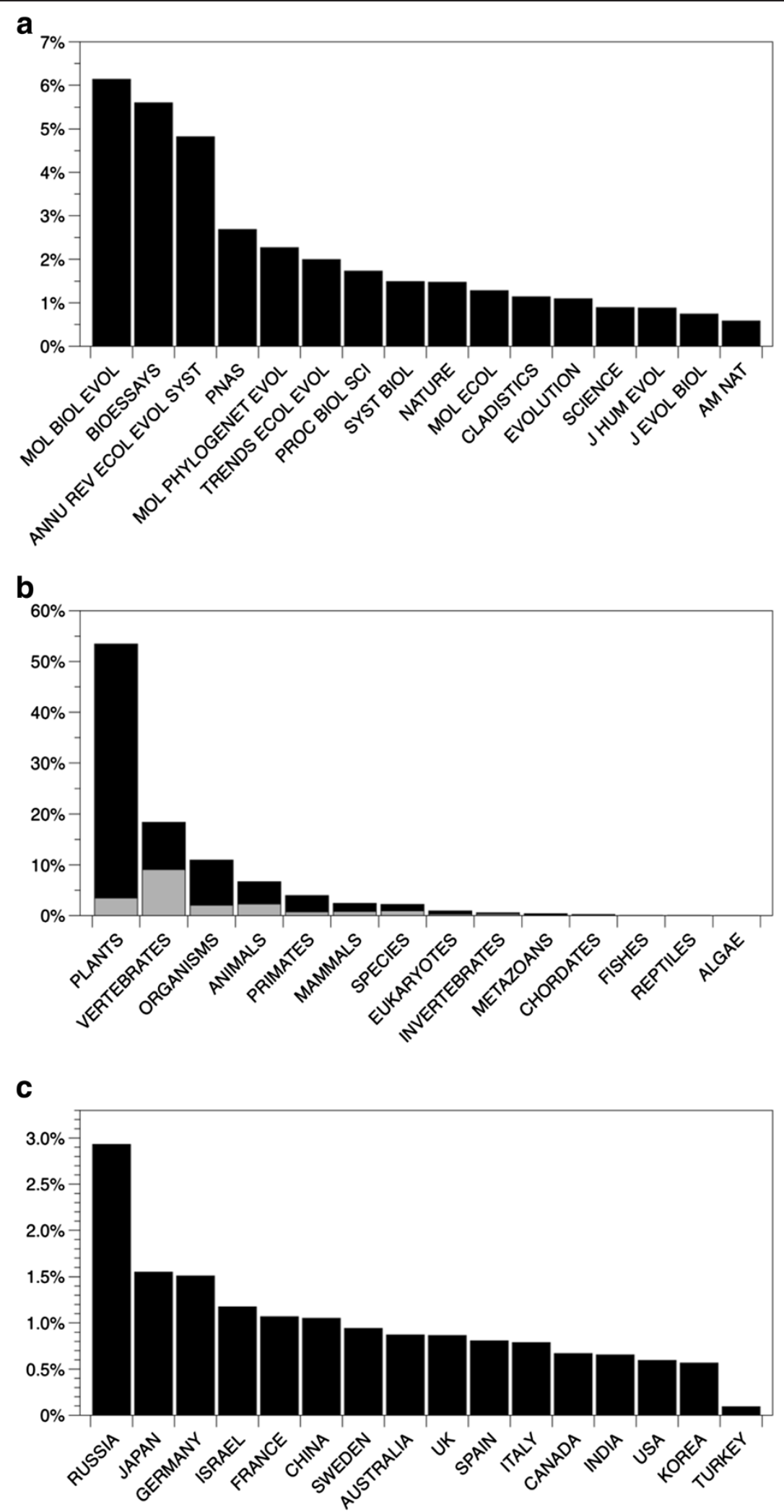

Figure 1 (See legend on next page.) 
(See figure on previous page.)

Figure 1 Results of data mining from biological articles published by 16 top professional journals between 2005 and 2010 , inclusive. (a) Positive hits, expressed as the percentage of the total number of biological articles published by each journal in the specified six-year interval, containing either in the title or in the main text at least one expression of the kind 'lower $X$ ' or 'higher $X$ ', with X taking the following values: species, organisms, eukaryotes, algae, plants, animals, metazoans, invertebrates, chordates, vertebrates, fishes, reptiles, mammals, primates. (b) Taxon frequency distribution of the articles mentioning lower (gray) or higher (black) representatives of a taxon ( $n=17,162$, performed on the PubMed data base). (c) The 16 top countries represented in the authors' affiliations of papers with "lower X" or "higher X" expressions (often with multiple hits per paper), listed in decreasing order of the percentage of positive hits in our search to the total number of articles from the same country presented in the mined (PubMed) database.

evolutionary biology; on the other hand, it is in this field that a chance of inattentively using this language is highest. Most of life sciences outside evolutionary biology, inclusive of phylogenetics and systematics, deal with a narrow selection of model organisms only, thus a paper in these disciplines will not often extend to comparisons between different organisms, one of which the author would be tempted to regard as lower or higher than others.

Articles with scala naturae language were particularly frequent in Molecular Biology and Evolution (6.14\%), BioEssays (5.6\%) and Annual Review of Ecology Evolution and Systematics (4.82\%). The fact that two of these three journals are in an area of evolutionary biology shows that the use of pre-evolutionary language can survive even in the most renowned professional journals.

One of the possible causes of this occurences is the very widespread use of tree-building algorithms and the inclusion of tree-like graphs in papers other than those in phylogenetics and their less than critical interpretations by researchers without adequate training in tree-thinking. The articles identified through "lower X" or "higher X" searches (performed using PubMed's searching functions, within the 2005 to 2010 interval) reveal a diversity of (sub)disciplinary traditions, if we consider a breakdown of the results according to the values of the Xs. Botany (especially with $\mathrm{X}=$ plants) contributes substantially more than zoology to the total and researchers dealing with mammals, primates in particular, are more prone to contrast lower with higher representatives of their favorite group than are zoologists dealing with other animal taxa.

A still higher prevalence of progressionist language was already noted by Mogie (2000) among the titles of papers published between 1995 and 1999 dealing with plants (671) rather than animals (9) or eukaryotes (40).

The persistence of a greater use of terminology of scala naturae among botanists may be due to the fact that the cladistics revolution broke out within zoology and paleozoology and only later, and to some extent less systematically, extended to botany and paleobotany.

We also performed an analysis (using the PubMed database again) of the hits of the distribution of their authors by country. Of the 16 countries that contributed most to the set of articles retrieved through the scala naturae search, 12 contributed with percentages of their total publication output in the journals and years covered by our search ranging from around $1.17 \%$ to $0.57 \%$. These countries are Israel, France, China, Sweden, Australia, United Kingdom, Spain, Italy, Canada, India, United States of America and Korea. On the upper end of the distribution we find Germany (1.51\%) and Japan (1.55\%), distinctly distanced, however, by Russia, whose $2.93 \%$ witnesses perhaps a less efficient involvement of the national scientific community into the conceptual debates on evolution that have been extensively developed in Western countries over the past decades. A more convincing example of cultural divide, however, separates Turkey from the remaining countries.

The fact that Russia will present such high frequencies could be a long-term effect of Lysenkoism. This effect may have spread in East Germany. However, it is amazing to see how Germany, the country where Willi Hennig was born, is one of the most affected, as it is also Darwin's homeland, still more than the America of Intelligent Design. The data show that scala naturae is a concept more entrenched in Europe compared to countries with less Westernized cultures, such as India, Korea and Turkey. However, the phenomenon is never absent, because this science remains in the Western tradition and culture in which it fits, and also brings with it its evolutionary heritage if it is quite persistent, although similar to a variable extent.

\section{Conclusions}

Thus, the great chain of being is still with us, 153 years after Darwin (1859) published The Origin of Species, eventually paving the way to modern tree-thinking (O'Hara 1992; Crisp and Cook 2005).

This is perhaps the most redoubtable or more obviously questionable linguistic shortcoming of current biological literature, but not the only one. In particular, crude forms of adaptationism are also still with us (Caruso et al. 2012; Olson 2012), 33 years after Gould and Lewontin's paper on The Spandrels of San Marco and the Panglossian Paradigm (Gould and Lewontin 1979). Quantitative data from a scientometric analysis may help in developing a more critical attitude in this respect. A sound, quantitative 
appreciation of the extent to which progressionist language survives in scientific papers is the first, necessary step towards its eradication. As to how to eradicate it, we fully support the views and the efforts of Baum et al. (2005), Johnson et al. (2012), Werth (2012) and other authors, who have recently offered a range of solutions, all based on a robust training in tree thinking.

\section{Competing interests}

The authors declare that they have no competing interests.

\section{Authors' contributions}

The two authors have equally contributed to planning and writing the paper. ER performed the bibliometric search and analysis. Both authors read and approved the final manuscript.

\section{Authors' information}

ER and AM work at the Department of Biology, University of Padova, on diverse aspects of evolutionary biology.

Received: 23 April 2013 Accepted: 23 April 2013

Published: 28 June 2013

\section{References}

Baum, DA, Smith, SD, \& Donovan, SS. (2005). Evolution. The tree-thinking challenge. Science, 310(5750), 979-980.

Bonnet, C. (1745). Traité d'insectologie, ou observations sur les pucerons/sur quelques espèces de vers d'eau douce qui, coupés par morceaux, deviennent autant d'animaux complets. Paris: Durand.

Brooks, DR, \& McLennan, DA. (1991). Phylogeny, ecology, and behavior: a research program in comparative biology. Chicago: University of Chicago Press.

Carroll, SB. (2001). Chance and necessity: the evolution of morphological complexity and diversity. Nature, 409(6823), 1102-1109.

Caruso, C, Rigato, E, \& Minelli, A. (2012). Finalism and adaptationism in contemporary biological literature. Atti Ist Veneto Sci Lett Arti Cl Sci Mat Nat, $170(1-2-3), 69-76$.

Casane, D, \& Laurenti, P. (2013). Why coelacanths are not 'living fossils'. A review of molecular and morphological data. Bioessays, 35(4), 332-338.

Crisp, MD, \& Cook, LG. (2005). Do early branching lineages signify ancestral traits? Trends in Ecology \& Evolution, 20(3), 122-128.

Darwin, C. (1859). On the origin of species by natural selection, or the preservation of favoured races in the struggle for life. London: John Murray.

Dawkins, R. (1992). Progress. In EF Keller \& EA Lloyd (Eds.), Keywords in evolutionary biology (pp. 263-272). Cambridge, MA: Harvard University Press.

Gould, SJ. (1994). The evolution of life on the earth. Scientific American, 271, 85-91.

Gould, SJ. (1996). Full house. New York: Harmony.

Gould, SJ. (1997). Redrafting the tree of life. Proceedings of the American Philosophical Society, 141(1), 30-54

Gould, SJ, \& Lewontin, RC. (1979). The spandrels of San Marco and the panglossian paradigm: a critique of the adaptationist programme. Proc $R$ Soc Lond B, 205(1), 581-598.

Gregory, TR. (2008). Understanding evolutionary trees. Evo Edu Outreach, 1(2), 121-137.

Jenner, RA, \& Wills, MA. (2007). The choice of model organisms in evo-devo. Nature Reviews Genetics, 8(4), 311-319.

Johnson, NA, Lahti, LC, \& Blumstein, DT. (2012). Combating the assumption of evolutionary progress: lessons from the decay and loss of traits. Evo Edu Outreach, 5(1), 128-138.

Krell, FT, \& Cranston, PS. (2004). Which side of the tree is more basal. Systematic Entomology, 29(3), 279-281.

Lamarck, JB. (1809). Philosophie zoologique. Paris: Dentu.

Lankester, ER. (1880). Degeneration: a chapter in Darwinism. London: Macmillan.

Linnaeus, C. (1735). Systema naturae, sive regna tria naturae. Systematice proposita per classes, ordines, genera, \& species. Lugduni Batavorum: Apud Theodorum Haak.

Lovejoy, AO. (1936). The great chain of being: a study of the history of an idea. Cambridge, MA: Harvard University Press.

MacDonald, T, \& Wiley, EO. (2012). Communicating phylogeny: evolutionary tree diagrams in museums. Evo Edu Outreach, 5(1), 14-28.
McShea, DW. (1991). Complexity and evolution: what everybody knows. Biol Phil, 6(3), 303-324

McShea, DW. (1993). Evolutionary change in the morphological complexity of the mammalian vertebral column. Evolution, 47(3), 730-740.

McShea, DW. (1996). Metazoan complexity and evolution: is there a trend? Evolution, 50(2), 477-492.

McShea, DW. (2000). Functional complexity in organisms: parts as proxies. Biol Phil, 15(5), 641-668.

McShea, DW. (2001). Parts and integration: consequences of hierarchy. In JBC Jackson, S Lidgard, \& FK McKinney (Eds.), Evolutionary patterns: growth, form, and tempo in the fossil record (pp. 27-60). Chicago and London: University of Chicago Press.

McShea, DW, \& Brandon, RN. (2010). Biology's first law: the tendency for diversity and complexity to increase in evolutionary systems. Chicago: University of Chicago Press.

Meir, E, Perry, J, Herron, JC, \& Kingsolver, J. (2007). College students' misconceptions about evolutionary trees. The American Biology Teacher, 69(7), 71-76.

Minelli, A. (2003). The development of animal form: ontogeny, morphology, and evolution. Cambridge, UK: Cambridge University Press.

Mogie, M. (2000). Historical baggage in biology: the case of 'higher' and 'lower' species. Bioessays, 22(9), 868-869.

O'Hara, RJ. (1992). Telling the tree: narrative representation and the study of evolutionary history. Biology and Philosophy, 7(2), 135-160.

O'Hara, RJ. (1997). Population thinking and tree thinking in systematics. Zool Scr, 26(4), 323-329.

Olson, ME. (2012). The developmental renaissance in adaptationism. Trends in Ecology \& Evolution, 27(5), 278-286.

Omland, KE, Cook, LG, \& Crisp, MD. (2008). Tree thinking for all biology: the problem with reading phylogenies as ladders of progress. BioEssays, 30(9), 854-867.

Ruse, M. (1996). Monad to man. Cambridge, MA: Harvard University Press.

Spencer, H. (1891). Essays: scientific, political and speculative. Library edition, containing seven essays not before republished, and various other additions (Vol) (1st ed.). London: Williams and Norgate.

Werth, A. (2012). Avoiding the pitfall of progress and associated perils of evolutionary education. Evo Edu Outreach, 5(2), 249-265.

doi:10.1186/1936-6434-6-18

Cite this article as: Rigato and Minelli: The great chain of being is still here. Evolution: Education and Outreach 2013 6:18.

\section{Submit your manuscript to a SpringerOpen ${ }^{\odot}$ journal and benefit from:}

- Convenient online submission

- Rigorous peer review

- Immediate publication on acceptance

- Open access: articles freely available online

- High visibility within the field

- Retaining the copyright to your article

Submit your next manuscript at $\gg$ springeropen.com 